\title{
EL SONETO "VUELA MI ESTRECHA Y DÉBIL ESPERANZA”': TEXTO, CONTEXTOS Y ENTRAMADO INTERTEXTUAL
}

Se propone aquí una lectura crítica del soneto "Vuela mi estrecha y débil esperanza", inserto en la comedia La entretenida ${ }^{1}$, con el propósito de examinar una de esas joyas poéticas cervantinas representantes en lengua de la "bellísima doncella" del poeta-paje en La gitanilla, de la ninfa "universal señora" en el Viaje del Parnaso (caps. 4 y 8) y de la “doncella tierna" en el Quijote de 1615 (cap. 16) ${ }^{2}$. El texto, desgajado de la obra que le sirve de montura, constituye un enunciado coherente de validez autónoma, pe-

${ }^{1}$ En Ocho comedias y ocho entremeses nuevos, nunca representados, Madrid, 1615.

${ }^{2}$ Fue la poesía la forma artística más amada por Cervantes, y la que menos se ha estudiado. Bibliografía fundamental: Ricardo Rojas, "De Cervantes considerado como poeta", Introducción a Poesias de Cervantes, Buenos Aires, 1916, pp. viii-cii; y Cervantes, Buenos Aires, 1948 (ya escrito en 1924); José Manuel Blecua, "Garcilaso y Cervantes', Cuadernos de İnsula (1947), pp. 141-151, y, bajo pseudónimo J. M. Claube, "La poesía lírica de Cervantes", Cuadernos de Insula (1947), pp. 151-187, Gerardo Diego, "Cervantes y la poesía", $R F E, 32$ (1948), 213-236; LuIs CernudA, "Cervantes poeta", en Poesia y literatura, Seix Barral, Barcelona, 1964; Vicente Gaos, "Cervantes, poeta", en Claves de literatura española, Guadarrama, Madrid, 1972; revisado, se incluye en Cervantes. Novelista, dramaturgo y poeta, de 1979, pp. 269-281; Adriana Lewis Galanes, "La poesía de Miguel de Cervantes", en Miguel de Cervantes Saavedra. Poesia, Ebro, Zaragoza, 1972, pp. 15-38; Elias L. Rivers, "Viaje del Parnaso y poesías sueltas", Suma Cervantina, Tamesis, London, 1973, pp. 119-147; Alberto Sánchez, Cervantes, poeta, Publicaciones del Instituto Nacional de Bachillerato Cervantes, Madrid, 1974; y Vicente GaOs, Introducción a la ed. Poesías completas de Cervantes, Castalia, Madrid, 1981. En la colección de ensayos M. CRiado de VAl (ed.), Cervantes. Su obra y su mundo, Edi-6, Madrid, 1981, se circundan a la poesía: AdRIANa Lewis Galanes, "Cervantes: el poeta en su tiempo", pp. 159-178; AndrÉs AMOrós, "Los poemas de El Quijote", pp. 707-716; y EliAS L. RIVERs, "Cervantes y Garcilaso", pp. 963-968. En preparación hace años, y presto a salir, mi estudio $E l$ plano de la belleza: la expresión poética de Miguel de Cervantes es resultado de un cxamen serio de cuarenta y siete años de persistencia cervantina en escribir poesía. 
ro la exploración de las relaciones extratextuales que anclan al soneto en tiempos-espacios determinados amplía su potencialidad significativa y nos permite presenciar el proceso creador del poeta.

El texto dice:

Vuela mi estrecha y débil esperanza con flacas alas y, aunque sube el vuelo a la alta cumbre del hermoso cielo, jamás el punto que pretende alcanza.

Yo vengo a ser perfecta semejanza de aquel mancebo que de Creta el suelo dejó y, contrario de su padre al celo, a la región del cielo se abalanza.

Caerán mis atrevidos pensamientos, del amoroso incendio derretidos, en el mar del temor turbado y frío;

pero no llevarán cursos violentos, del tiempo y de la muerte prevenidos, al lugar del olvido el nombre mío.

$$
\text { (I, vv. 245-248, f. } \left.170 \mathrm{v}^{\circ}\right)
$$

El mensaje, volcado hacia sí mismo, internaliza el mito de Ícaro, no como lo configuró el romano Ovidio (Metamorfosis VIII, $183-259)^{3}$, ni con el sesgo moralizante que se le dio al cristiani-

${ }^{3}$ Se hace necesaria aquí una relectura del texto de Ovidio; es una relación centrada en Dédalo: su aborrecimiento de la isla de Creta, la fabricación de alas artificiales para escapar de allí con su hijo, su preceptoría de Ícaro en la imitación de las aves, el aviso de volar "la medianía entre el mar y el sol", la advertencia desechada por el arrobado puer audaci en mitad del camino, la caída de Ícaro al mar que lleva su nombre, el lamento del padre, el entierro de Ícaro y la alegría de la perdiz sobre el sepulcro. Se cierra así un ciclo en la vida de Dédalo que comenzó en Atenas donde, envidioso de los inventos mecánicos de su sobrino, empujó a éste a la muerte desde la Acrópolis: muerte definitiva impedida por Palas, quien transformó al joven en una perdiz. En fin, el texto ovidiano gira sobre el tema de crimen-y-castigo ilustrado en Dédalo, doble ofensor de la naturaleza en el asesinato de su sobrino y en el atentado de duplicar las aves: delitos castigados por Némesis, la justicia retributiva. Nótese que el vuelo y la caída de Ícaro son incidentales en la fábula en Ovidio. El soneto cervantino no duplica el hilo narrativo ovidiano; ni siquiera reproduce la anécdota acerca del vuelo de Ícaro, pues éste se ha reducido ya a simple recurso retórico, a símil/"semejanza". 
zarlo ${ }^{4}$, sino a la manera cervantina: el eje del soneto podrá ser la audacia icariana, lugar común en la literatura de los siglos XvI y XviI, pero su blanco es la justificación hazañosa del ser, el voluntarismo o libertad de labrarse su propio destino el hombre y la mujer aunque lo ejecutado resulte en un desastre personal ${ }^{5}$. El

${ }^{4}$ Cervantes bien pudo manejar las Metamorfosis traducidas al español por Jorge de Bustamante (Libro del Metamorphoseos y fábulas del excelente poeta y philósopho Ovidio, noble caballero patricio romano, s.f.; la edición princeps es anterior a 1546), o la del licenciado Pedro Sánchez de Viana (Las Transformaciones de Ovidio, Valladolid, 1589). Posiblemente conoció las traducciones en verso de Antonio Pérez Sigler (Los Quince Libros de los Metamorphoseos del excelente poeta latino Ovidio, Salamanca, 1580; reeditada en Burgos, en 1609, con la añadidura de un diccionario poético) y de Felipe Mey (Del Metamorfoseos de Ovidio, Tarragona, 1586; imitación servil de las versiones italianas por Lodovico Dolce, de 1539 y de Giovanni Andrea dell' Anguillara, de 1554). Tal parece como si, en los años en que compone la Segunda parte del Quijote, Cervantes ya estuviese hastiado de la españolización/cristianización/refundición de Ovidio, y burlescamente nos lo deja saber por boca de un estrafalario pedante, quien queda sin nombre y es sólo conocido como el primo de un licenciado diestro en esgrima: "Otro libro tengo también, a quien he de llamar Metamorfoseos, o Ovidio Español, de invención nueva y rara; porque en él, imitando a Ovidio a lo burlesco, pinto quién fue la Giralda de Sevilla y el Ángel de la Madalena, quién el Caño de Vecinguerra, de Córdova, quiénes los Toros de Guisando, la Sierra Morena, las fuentes de Leganitos y Lavapiés, en Madrid, no olvidándome de la del Piojo, de la del Caño dorado y de la Priora; y esto, con sus alegorías, metáforas y translaciones, de modo que alegran, suspenden y enseñan a un mismo punto" (cap. 22). No es de extrañar que en años cuando se ha trivializado a Ovidio hasta la saciedad, o cuando se ha reorientado la mira del romano para hacerla acorde a las exigencias contrarreformistas (véase la Philosophia secreta de JUAN PÉrez De Moya, publicada en 1599: cuasipoliantea de poetas cristianoparnasistas), Cervantes elabore ese soneto de La entretenida sin tendencias moralizantes.

${ }^{5}$ Fuera de lo fabulado, regido por las coordenadas ideológicas cervantinas, sí se halla una proyección del Ícaro arquetípico en el impulso dirigente de los actos y discursos de Don Quijote: es el móvil que hace borroso el linde entre la locura y la cordura. Un examen horizontal y vertical de los mundos creados por Cervantes señala esa conducta como puntal de lo que constituye un ser humano admirable: en La Galatea, Elicio dispuesto a luchar por la amada a pesar de que sabe que es un riesgo, amén de la hilera de personajes como don Fernando de Saavedra en El gallardo español, Julia y Porcia en El laberinto de amor, Ricardo en El amante liberal, Recaredo en La española inglesa, Tomás de Avendaño en La ilustre fregona, Teodosia y Leocadia en Las dos doncellas, al lado de Preciosa en La gitanilla, cuya pretensión se plasma en canto ("Quiero ver si la belleza / tiene tal prerrogativa / que me encumbre tan arriba / que aspire a mayor alteza'). El voluntarismo adquiere matices ambiguos en Pedro de Urdemalas, comedia donde las presunciones de Belica, la gitana que resulta ser de sangre noble, y Pedro, el hijo de la piedra cuya ascendencia nunca sa- 
encabalgamiento simple de dos versos, primer verso con primera mitad del segundo, reproducido en orden inverso tocante a la segunda mitad del segundo verso con el tercero, crea una cadencia interna de signo reflexivo que permite la aceptación sin desesperación alguna del no lograr plenamente lo deseado tan decisivamente informado en el cuarto verso: postura filosófica impedidora del adocenado fatalismo barroco. El encabalgamiento de tres versos en tensión, en el segundo cuarteto, interrumpido por un aparte incidental, para remontarse impetuosamente en el último verso de la estrofa, atiranta la consideración, estrecha más la esperanza y se desploma en el "Caerán" del primer terceto, cuyo dramatismo concretiza lo previamente aceptado. El último terceto, rítmicamente gémino al anterior, remite la reflexión a lo que le otorga razón de ser al quehacer, al derrotar la derrota con el verbo, con el yo hecho nombre, con el acto poético mismo ${ }^{6}$. El soneto, vuelo-despeñamiento-salvación, permanece, aparte del entorno verbal que asedia sus confines expresivos y afectivos, y se autosignifica.

Empero, esa función poética, aunque autónoma, no controla el empleo del poema fuera de la esfera de los catorce versos. El macrotexto, la comedia La entretenida en la que se incluye el soneto, le concede una función referencial dentro de su propia ficción poética. Se introduce Cardenio, estudiante pobretón de "'manteo y sotana", al hecho escénico con el soneto aquí estudiado. Habla consigo mismo en voz alta mientras su acompañante, Torrente el capigorrón, va comiendo un membrillo, ajeno al lirismo del discurso escuchado por el público ${ }^{7}$. Sin otra interrupción que la del

brá, llegan a conclusión en los paralelos niveles de la historia (Belica) y la ficción (Pedro): antagonía complementaria distintiva del pensamiento de Cervantes, como señalo en "Popularismo estilizado: una travesura cervantina", MLN, 88 (1973), 337-346.

${ }^{6}$ En el soneto analizado, el mito permanece al margen de la mitificación, construida por similitud, no por equivalencia, y fuera de la circunstancia histórica del personaje monologante. Más allá de los catorce endecasílabos, la mitificación se deshace al chocar con lo particular histórico, pero no el núcleo del mito: procedimiento demitificador de signo constructivo ya que salva lo valioso del mito. Debe entenderse así el epitafio merecido por Don Quijote en 1615: "Yace aquí el Hidalgo fuerte / que a tanto estremo llegó / de valiente, que se advierte / que la muerte no triunfó / de su vida con su muerte".

7 Técnica de violentación por contraste tan efectiva en el Quijote: siempre, mientras Don Quijote escucha, lee o elabora un poema, Sancho come, duerme, se desaparece o, como en el episodio de la maleta de Cardenio en Sierra Morena (I, 23), no entiende la "trova" (confunde "Fili" con "hilo"). 
punto final del soneto, Cardenio continúa:

¿Comes? ¡Buena pro te haga!

¿La misma hambre te tome!

(I, vv. 259-260)

El derrumbamiento al fondo de la condición estudiantil quiebra la ilusión poética y desplaza el impulso icarista hacia lo particular histórico determinante de la acción dramática que le toca representar a ese galán no tan galano. Un examen de cómo el mito de Ícaro se proyecta dentro de la comedia muestra que Gardenio, quien se asume "perfecta semejanza" de aquel atrevido mancebo, se caracteriza mayormente por la inacción: su único acto audaz ha sido falsificar su identidad, hacerse pasar por el hijo de un rico indiano para así obtener la mano de la bella, rica y esquiva Marcela de Almendárez, pero tras llevar a cabo el engaño y encontrarse alojado en la casa de la mujer deseada se pasa los días solo, holgándose a pierna suelta ${ }^{8}$. Vivir "regalado" lo llama Marcela, invirtiéndose así en el macrotexto lo que se infirió en el soneto $^{9}$. De ese choque entre la poesía y la historia surge lo patético risible que anima las texturas burlescas de Cervantes ${ }^{10}$.

${ }^{8} \mathrm{El}$ polo opuesto de esta actitud es Grisóstomo, el cortesano-pastor desesperado en el Quijote de 1605 (caps. 12-14), quien llega al suicidio (en la canción, al menos, pues la historia narrada queda ambigua) y solicita se quemen sus poemas, a imitación de Virgilio. Tanto Grisóstomo como el Cardenio de La entretenida coinciden en cuanto a actos de transformación social (Grisóstomo en pastor y Cardenio en indiano: falsos ambos) y en cuanto al decir-sinhacer que los lleva al fracaso, pues ambos viven ensimismados sin acometer la empresa autoasignada. Nos parece interesante que también coincidan en lo tocante al nombre, Marcela, de la mujer que aman a lo divino, y que en el ámbito económico que cada uno se inventa, Grisóstomo-rico viva como pobre mientras Cardenio-pobre viva como rico.

${ }^{9}$ Procedimiento parecido al presente en los capítulos 18-21 en el Quijote de 1615: el mito ovidiano de Píramo y Tisbe en el soneto de don Lorenzo de Miranda (18) choca con la particularización del mito dentro del mundo social en que transcurre la historia de Basilio-Píramo, Quiteria-Tisbe y CamachoLeona (19-21). Los resultados son distintos, por supuesto: el voluntarismo en el soneto de La entretenida se opone a la inacción de Cardenio en la acción dramática, mientras que el voluntarismo en el soneto parnasista de la Segunda parte del Quijote, aunque también irreflexivamente puesto en práctica ("Salió el deseo de compás..." v. 9), se concierta con el ingenio en el deseante Basilio para llegar al éxito mediante un plan de acción meditadamente efectuado.

10 Aquí apremia la advertencia de no confundir la reducción estimativa en manos de Cervantes con un total rechazo de todo lo que se asocie con el 
La comedia en sí, parodia bufa del teatro convencional de época, se remite a otras significaciones fuera de lo escenificado, como ya ha indicado Juan Bautista Avalle-Arce"1, y el soneto "Vuela mi estrecha y débil esperanza", aparte de su valor autorreferencial y su utilidad extra-microtextual en La entretenida, se vierte hacia un mundillo literario suplementario donde es sólo uno de los múltiples referentes orientados al contexto modificador de la comedia. A primera vista el soneto parece tener importancia sólo formal en relación al contexto socioliterario, a la comedia lopesca mofada por Cervantes al embutir la suya con seis sonetos, con octavas líricas remitentes a polémicas de invención poética y con largos parlamentos en versos sueltos o en altisonantes estrofas que quiebran el decoro al no guardar las reglas de armonía entre la materia y el tono; empero, la naturaleza misma del soneto, el aprovechamiento de una figura mítica insólita en el repertorio de recuerdos clásicos cervantinos ${ }^{12}$, obliga a la búsqueda de otra esfera contextual cuya dilucidación consienta apresar el sentido cabal del poema.

Una pesquisa dentro de la tradición literaria en que Cervantes se ubica, restringiéndonos al uso de tópicos/temas neo-ovidianos, conduce a su poeta predilecto, Garcilaso de la Vega, quien había dispuesto la trayectoria de la interpretación de Ícaro como mozo desastrado en el soneto "Si para refrenar este deseo", al insinuar en el primer terceto:

¿qué me ha de aprovechar ver la pintura d'aquél que con las alas derretidas, cayendo, fama y nombre al mar ha dado ${ }^{13}$,

sujeto despoetizado o degradado: recordemos que el Quijote desterrará a carcajadas los disparatados libros de caballerías, pero salvará lo artísticamente valioso en ellos, amén de resguardar el espíritu caballeresco.

${ }^{11}$ En "On La entretenida of Cervantes", MLN, 74 (1959), 418-421.

12 Hay sólo dos alusiones directas a Ícaro en toda la obra de Cervantes. Aparece primero en La Galatea (Libro I; habla Tirsi): " -no es maravilla que, cual nuevos ícaros, caigan abrasados en el río de las miserias, de las cuales no tendrá culpa Amor, sino su locura'. Ahí se articula un lugar común verbal: a un decir es un icaro por es un loco, sin asignación alguna al personaje mítico y su contorno narrativo (nótese: Cervantes usa el plural, "ícaros", indicando una colectividad aspirante a algo superior a sus merecimientos). La segunda alusión es la que está implícita en el soneto aquí estudiado. La huella de Ovidio en Cervantes es trazada por Rudolph Schevill en "Ovid and the Renaissance in Spain", MPh, 4 (1913), 1-268.

${ }^{13}$ Poesías castellanas completas, ed. Elias L. Rivers, Castalia, Madrid, 1969, 
La alusión aquí es mera referencia a un caso catastrófico, para permitirse el poeta un lamento de su imposibilidad de aprender de la experiencia ajena. La ascendencia de Garcilaso en Cervantes será patente en su obra, pero en cuanto al enfoque dado a la figura de Ícaro no se aproximan. A otra mira distinta de la de Garcilaso apunta Fernando de Herrera, manantial copioso donde bebió Cervantes desde su mocedad hasta su vejez, en el soneto:

¡O cómo vuela en alto mi deseo sin que de su osadía el mal fin tema!; que ya las puntas de sus alas quema, donde ningún remedio al triste veo.

Que mal podrá alabarse del trofeo, si, estando ufano en la región suprema del fuego ardiente, en esta banda estrema cae por su siniestro devaneo.

Debía en mi fortuna ser ejemplo Dédalo, no aquel joven atrevido que dio al cerúleo piélago su nombre.

Más ya tarde mis lástimas contemplo; pero si muero, porque osé, perdido, jamás a igual empresa osó algún hombre ${ }^{14}$.

Para Herrera, Ícaro es imagen de la audacia irresistible, de una soberbia divinizante que irremediablemente decide su conducta, mientras que para Cervantes, en el soneto de La entreteni$d a$, Ícaro es representación de un deliberado aspirar a ser más, animado con y fortificado por el conocimiento de la perpetuación del nombre propio. El soneto de Herrera sí suscita asociaciones con frases cervantinas en el soneto cuya lectura crítica nos concierne: "vuela [...] mi deseo" (H) con "Vuela mi [ . . ] esperanza" (C). Ambos mencionan "alas" en el primer cuarteto, y "región suprema" $(\mathrm{H})$ con "región del cielo" $(\mathrm{C})$, además de la mutua alusión al hecho de perdurar mediante el nombre. No obstante la

soneto XII (p. 48). Es la única alusión que hemos hallado en la obra de Garcilaso, quien prefiere el ejemplo de Faetón como designante de locura.

14 Sigo la edición de Vicente García de Diego, Poesias, Espasa-Calpe, Madrid, 1970, soneto XLIII, pp. 90-91. Ver texto y variantes en Rimas inéditas, ed. José Manuel Blecua, Madrid, 1948, pp. 24-25; coteja Blecua el soneto citado con un texto primitivo de 1578 (BNM, ms. 10.159). 
filiación lingüística entre Cervantes y Herrera -que con Garcilaso se limitaría a una lejanía conceptual entre "alas derretidas" (G) y "pensamientos [...] derretidos" (C)-, nuestra indagación tocante a la construcción icariana tiene que buscar la prosapia del soneto de Cervantes en otro venero.

Al repasar la poesía de los coetáneos a Cervantes, no encontramos una postura vital igual a la proposición icarista de éste. Lo que saltó a la vista fue una correspondencia muy extraña entre los recursos expresivos de que se vale Juan de Arguijo en sus sonetos clasicistas y los empleados en el soneto "Vuela mi estrecha y débil esperanza" de Cervantes. Sirva de ejemplo, de Arguijo:

Osaste alzar el temerario vuelo Ícaro, vanamente confiado en mal ligadas plumas y, olvidado del sano aviso, te acercaste al cielo,

donde el ardor del que gobierna a Delo, deshaciendo tus alas, despeñado te arrojó al mar, a quien tú nombre has dado y él sepultura a ti en su hondo suelo.

Por más cierto camino el sabio viejo de tal peligro discurrió seguro, y a Febo dedicó el cumano templo.

iOh, si seguir supieras su consejo que no quedara en tu castigo duro de las rendidas alas el ejemplo! $(57)^{15}$

Nótese la coincidencia de ambos poemas en cuanto a la técnica de encabalgamiento simple de dos versos que escinde el ritmo métrico creando modulaciones superantes del haz rítmico obligatorio del soneto. Igual se halla en ambos poemas el uso de un encabalgamiento de tres versos en tensión: recurso designatorio de la poesía de Arguijo, y no de la de Cervantes. A pesar de que el soneto "Vuela mi estrecha y débil esperanza" no tiene reciprocidad conceptual con "Osaste alzar el temerario vuelo" -lo que es en Cervantes un soliloquio internalizador del mito de Ícaro, es en Arguijo un apóstrofo amonestante a un remedo de 1972 .

15. Sigo la edición de Stanko B. VRanich, Obra poética, Castalia, Madrid, 
Ícaro-, y que las técnicas articulatorias compartidas, aunque singularizantes de Arguijo, no son privativas de éste, lo que intuitivamente notamos adquiere validez documental al cotejar los sintagmas en el soneto cervantino con expresiones afines empleadas por poetas desde 1543 hasta 1615: se encontró que casi todos esos giros expresivos del soneto enfocado se usaron reiteradamente, igual o en forma parecida, pero uno de ellos, "flacas alas", parece ser propiedad exclusiva de Arguijo.

En Garcilaso de la Vega se encuentran: "alas derretidas", “prestas alas", "flaca parte", “flaca tristeza". En Herrera, "prestas alas", "alas rojas", "alas quemadas", "alas presurosas", " "doradas alas", "alas variadas", "flaca osadía", "flaca vista", "flaco vuelo", "flaca suerte", "flaco fundamento", “flaca nave", "“flaco son", "flaca esperanza". En Francisco de Aldana, "firmes alas", y múltiples combinaciones de alas y de flacas pero no alas flacas. Y así otros poetas. Cervantes, a su vez, usa a lo largo de su obra "flaca naturaleza", "esperanza [...] flaca", "voz [...] flaca", "flaco ingenio", "flaca disculpa", "flaca [...] persuación", "fuerzas [...] flacas", "sujeto flaco", "flacas ocasiones", pero "flacas alas" únicamente en el soneto parnasista en La entretenida. En Juan de Arguijo, "flacas alas" aparece como símbolo de la ambición y la transgresión, y bien podría llamarse su firma dentro del registro de giros verbales que preparamos al explorar la lengua poética de los precursores y coetáneos de Cervantes. Así en Arguijo:

Por mejor suerte no importuna al cielo, ni se muestra envidioso a la que tienen los que con ansia de subir sostienen en flacas alas el incierto vuelo.

(167; ref. a Eumelo)

Mas enfrene mi vuelo en su carrera la memoria del joven imprudente y flacas alas en su mal rendidas.

(197; ref. a Ícaro)

Tocante a esta correspondencia entre Cervantes y Arguijo, honradamente hay que admitir que por sí sola es muy flaca evidencia de filiación. Se da en Cervantes, en cuanto se refiere a su selección de una raíz o un intertexto literarios, una inconstancia 
que impide el diagnóstico. Por otra parte, el culto a la lengua de Garcilaso y de Herrera durante esa época frustra cualquier intento de establecer con exactitud un tránsito intertextual determinado. Verbigracia, la locución "temor turbado y frío", en el soneto de Cervantes que investigamos, coincide parcialmente con el "perezoso miedo que me enfría" (175) en otro soneto de Arguijo ("Atrevimiento en la desesperanza"), pero dado que "frío temor", "horror frío" y "frío miedo" son expresiones reiteradas en Herrera, fuente tanto de Cervantes como de Arguijo, tenemos que reconocer impracticable el postular aquí un nexo intertextual entre éstos ${ }^{16}$.

Entonces, ¿cómo explicar el que Cervantes incluya en su soneto técnicas formales, giros verbales y contrasignos a las preferencias conceptuales de Arguijo? Se nos impone la tarea de escudriñar en asuntos extraliterarios, en el mundillo de partidismos y rencillas del periodo en que se escribió el soneto "Vuela mi estrecha y débil esperanza".

Aparte de los dardos cervantinos enfilados hacia la comedia lopesca, se reconoce El peregrino en su patria, malograda novela de Lope de Vega, como también blanco de las burlas del "manco sano". Se ha examinado, a su vez, el Viaje del Parnaso como epopeya bufa sólo comprensible dentro del contexto socioliterario a que apunta. Conexa con el Peregrino, hay que inscribir la Primera parte de las flores de poetas ilustres de España, dividida en dos libros. Ordenada por Pedro Espinosa, natural de la ciudad, de Antequera ${ }^{17}$, en el registro de obras que suscitan la indignación cervantina. No se debe olvidar que Cervantes se consideraba ante todo Poeta, insistiendo en ello a lo largo de su quehacer literario aunque nuestro hoy crítico le preste tan poca atención a esa expresión suya. Amante "desde [sus] tiernos años [d]el arte dulce en la agradable poesía" (Viaje, 4), y más cercano a Garcilaso y a Herrera que a los poetas y a los poetastros de su tiempo, el Poeta tuvo que resentir el doble

${ }^{16}$ Hay ciertas coincidencias difíciles de explicar entre Cervantes y Arguijo tocante a giros verbales. Resalta el aparte "¡oh estraño caso" en el soneto "a la fábula o historia de Píramo y Tisbe" ficticiamente compuesto por don Lorenzo de Miranda, y recitado por este personaje en el capítulo 18 del Quijote de 1615: es un aparte muy común en la obra poética de Arguijo. El tópico de Píramo y Tisbe es también uno frecuentemente usado/aludido por Arguijo. Encuentro el mismo aparte en un soneto de estirpe virgiliana por LuIs Martín de la Plaza en Flores de poetas ilustres de 1605 (eds. Juan Quirós de los Ríos y Francisco Rodríguez Marín, Sevilla, 1896; el núm. xv).

${ }^{17}$ Luis Sánchez, Valladolid, 1605. 
rechazo representado por la colección de "poetas ilustres" realizada por Pedro Espinosa: no es uno de los elegidos como ilustres y sí uno de los aludidos en el prólogo "Al lector" del antequerano.

La dedicatoria de Flores de poetas ilustres al Duque de Béjar, a quien Cervantes le dedicó también el Quijote de 1605, insinúa que fue ésa resultado de una petición de contribuciones, seguida de un proceso de selección:

De los ilustres ingenios que oy en España profesan el estudio de la Poesía, he juntado (con alguna trabajosa diligencia) las más luzidas flores: y aora (dichosamente) me rinden colmado fruto [...] cumplo con la obligación que debo a tan ilustres ingenios (7).

En la recopilación selectiva de Espinosa se le explica "Al lector": "tanto he hecho en no escribir cosa mala, como en admitir esto bueno: porque para sacar esta Flor de harina, he cernido dozientos cayzes de Poesía, que es la que ordinariamente corre" (3).

El proceso de elección y criterio para el enjuiciamiento polariza el antes y el ahora:

trabajo tan grande [el mío], como es, escalar el mundo con cartas [convocación], y después de pagar el porte, hallar en la respuesta [colaboración a considerarse] la glossa de Vide á juana estar lavando, o algunas redondillas de las de las turquesas de Castillejo, o Montemayor (venerable reliquia de los soldados del tercio viejo), o cuando más algún Soneto cargado de espaldas, y corto de vista, que no vee palmo de tierra, que éstos ya gozaron su tiempo: mas aora los gentiles espíritus del nuestro (como parecerá en este libro) nos han sacado de las tinieblas desta acreditada inorancia, y yo, por no exceder los rigurosos preceptos de los Prólogos, cubriré su alabanças con el velo del silencio (3).

Cervantes tuvo que reconocerse entre los que quedaron dentro del harnero, entre los poetas de redondillas, entre los que persistían en la primacía de la expresión poética pastoril, entre los "soldados de tercio viejo", autor de sonetos que "ya gozaron su tiempo"18.

${ }^{18}$ Sorprende que Rodríguez Marín, cervantista, detectivesco editor del Viaje del Parnaso, al igual que de las Flores de poetas ilustres de 1605 y de la Segunda Parte de las Flores de poetas ilustres de España, ordenada por D. Juan Antonio Calderón (de un códice de 1611), no haya notado la relación de soslayo entre el gran Miguel y los grupos granadino y antequerano. Las citas nuestras se remiten al "Prólogo al lector" en Novelas ejemplares, Juan de la Cuesta, Madrid, 1613, 
Dentro de este contexto debe entenderse el noveno terceto del Capítulo Primero en el Viaje del Parnaso:

Yo, que siempre trabajo y me desvelo por parecer que tengo de poeta la gracia que no quiso darme el cielo.

Estos tan frecuentemente aludidos y malentendidos versos introducen al lector a la estructura irónica que apuntala toda la obra, y deben leerse sin desgajarse de los tres tercetos de carácterijocosodesiderativo que remiten al "Yo" inicial:

quisiera despachar a la estafeta mi alma, o por los aires, y ponella sobre las cumbres del nombrado Oeta,

pues descubriendo allí la bella corriente de Aganipe, en un saltico pudiera el labio remojar en ella,

y quedar del licor süave y rico el pancho lleno, y ser de allí adelante poeta ilustre, o al menos manifico. (Las cursivas son mías.)

La indignación traducida en risa en el Viaje del Parnaso ${ }^{19}$ ya había pasado por el aplacador tamiz de la mofa implícita en la comedia La entretenida ${ }^{20}$, pues es en ésta donde Cervantes sublima la contrariedad ocasionada por El peregrino en su patria (1604) de

donde al autorretratarse utiliza sus impedimentos físicos ("algo cargado de espaldas", "no muy ligero de pies", "soldado de muchos años") para validarse ante los poetas jóvenes pertenecientes al grupo andaluz (al cual pertenecía el poeta y pintor Juan de Jáuregui, cuyo retrato de Cervantes juguetonamente inventado por el socarrón prologuista, "bien pudiera" grabarse en el libro si ése "le diera" lo que sólo existe en hipótesis. Fundamento mis conclusiones acerca de la debatida relación Cervantes-Jáuregui en ENRIQUe LAFUENTE FERRARI, La Novela ejemplar de los retratos de Cervantes, Madrid, 1948. El primer párrafo de ese prólogo se encamina por rodeos a "no tener punto preciso ni determinado las alabanzas ni los vituperios" (última frase).

19 Viuda de Alonso Martín, Madrid, 1614.

${ }^{20}$ Coincido con Rudolph Schevill y Adolfo Bonilla, en "Introducción" a Obras completas de Miguel Cervantes Saavedra, Imprenta de Bernardo Rodríguez, Madrid, 1931, t. 6, quienes fechan La entretenida entre 1604 y 1611. Milton A. Buchanan llega a la misma conclusión en "The works of Cervantes and their dates of composition", Transactions of the Royal Society of Canada, 
Lope y las Flores de poetas ilustres (1605) recopiladas por Espinosa. Juan de Arguijo, uno de los poetas más prestigiosos de Sevilla ${ }^{21}$, es el factor empalmante de El peregrino y las Flores. Lope de Vega le dedicó varias obras, lo señaló como ilustre de Sevilla en La Arcadia, le presentó el manuscrito de El peregrino para que se lo criticase y, en seguimiento del soneto " $\mathrm{Al}$ marqués de Priego" (a quien le dedicó El peregrino) que iba con el retrato de Lope, le colocó su soneto encomiástico, dándole relieve al rico parnasista sevillano. Fue Arguijo, al igual, el poeta destacado por Espinosa para iniciar el Libro Primero de las Flores: ¡antepuesto a Góngora! Seis sonetos de corte clasicista por Arguijo se incluyen en las Flores de poetas ilustres.

Hay otra relación Peregrino-Flores que Cervantes irónicamente funde en el texto y el macrotexto de La entretenida aquí explora-

32 (1938), 23-29; refuerza dicha datación en "Cervantes and Lope de Vega: their literary relations", PhQ, 21 (1942), 54-64.

${ }^{21}$ Arguijo, después de Juan de Mal-Lara y Fernando de Herrera, fue uno de los escritores de mayor fama en Sevilla, a pesar de que su producción poética no es copiosa. Competía don Juan de Ochoa, ferviente anti-lopista, con Arguijo por la monarquía de la ciudad de Guadalquivir, y diversos cervantistas han especulado que Cervantes asistió a la Academia de Ochoa entre 1598 y 1602. Lope de Vega, acompañado de su amante Micaela de Luján, visitó Sevilla en varias ocasiones durante los años 1602 a 1604: estancias que motivaron tertulias, agasajos y un hervor poético del cual fue partícipe Arguijo; antes de noviembre de 1603, fecha en que Tomás Gracián Dantisco firmó la aprobación de El peregrino en su patria, Arguijo, a petición de Lope, enjuició el manuscrito y al parecer fue él quien convocó a sus partidarios a certificar el ilustre ingenio del dramaturgo-hecho-novelista con, como burlonamente dirá Cervantes en el Quijote de 1605, "la innumeralidad y catálogo de los acostumbrados sonetos, epigramas y elogios que al principio de los libros suelen ponerse" ("Prólogo"). Noticias de la tarea crítica asignada a Arguijo llegaron a oídos del partido adverso a Lope, de donde salió un disparo en décima de versos de cabo roto, atribuida ésta al rufianesco sevillano Alonso Álvarez de Soria por los estudiosos modernos, pero que en aquel momento se creyó un perdigón de la pluma de Cervantes; se teoriza que de ahí surgió el rompimiento entre éste y Lope. En su mundillo hispalense, despilfarra Arguijo la hacienda acumulada por su padre en el comercio con las Indias, y se encumbra como cabeza de una élite clasicista cuyas metas eran la ilustración de la lengua y la consecución del deleite estético mediante la rememoración de la complejidad del verso latino y el aprovechamiento de tópicos de Horacio, Virgilio, Ovidio y, por extensión al pasado helénico, Homero. Véanse José María Asensio, Don Juan de Arguijo. Estudio biográfico, Madrid, 1883; Cayetano Alberto DE LA BARRERA, "Nuevas noticias biográficas del insigne poeta sevillano D. Juan de Arguijo", Revista de España, 4 (1868), 265-274; R. Benítez Claros, "Introducción”, Obras completas de Juan de Arguijo, Santa Cruz de Tenerife, 1968, pp. 9-45; y la edición antes aludida, por Stanko Vranich. 
dos. En 1602, al visitar Lope de Vega a Antequera, donde fue festejado por el círculo poético al cual pertenecía Pedro de Espinosa, Luis Martín de la Plaza le dedicó dos sonetos: "Espíritu gentil quel alto Cielo" y "Hermosas ninfas que en alegre coro". Dentro de nuestra línea de estudio, nos interesa el primer soneto, ya que yuxtapone la figura de Ícaro a la de un divinizado Lope de Vega ${ }^{22}$. Al disponer Lope la edición de El peregrino, lo enmarcó con doce poemas encomiásticos preliminares y tres de remate tras el colofón. Aparece "Espíritu gentil quel alto cielo" al frente de los tres poemas de broche, pero falsamente atribuido al poetasastre-analfabeto Agustín de Castellanos, gran amigo de Lope ${ }^{23}$. Dicho fraude o descuido causó revuelo entre los poetas antequeranos, cuyo corifeo, Pedro Espinosa, ya para 1603, antes de hacerse público el desaire a Luis Martín de la Plaza, tenía ultimada

${ }^{22}$ El soneto reza: "Espíritu gentil que el alto cielo / asaltas con ingenio peregrino, / vuela seguro, pues el sol divino / te presta aliento, te respeta el vuelo. / Que no serás cual el audaz mozuelo / (bien que imitas el áspero camino), / que dando nombre al Ponto cristalino / fueron las ondas de su muerte el yelo. / Que las alas opuso al sol ardiente / de cera y de soberbia, pues con ella / al cielo presumió ponerle escalas. / Mas tú que llevas en la ilustre frente / el privilegio de su Dafne bella / puedes subir sin abrasar tus alas"'. Cuando IGNACIO DE TOLEDO y GODOY reúne en cuatro tomos, por los años de 16271938, la colección que hoy conocemos como Cancionero antequerano, incluye el soneto de Luis Martín de la Plaza con la nota: "Del mismo [Luis Martín de la Plaza] a Lope de Vega estando en Antequera, aunque él, ingratamente, lo puso en su libro de El peregrino con nombre de otro autor" (eds. Dámaso Alonso y Rafael Ferreres, CSIC, Madrid, 1950, pp. 58-59). Las variantes en el texto copiado en el Cancionero son: v. 5, "como" por cual; v. 8, "halló en" por fueron; v. 9, "Que él las" por Que las; y v. 12, "docta frente" por ilustre frente.

${ }^{23}$ Andaba de boca en boca ese mismo año de 1605 en que se publicó la antología de ilustres de Espinosa el hecho risible del premio conferido al poetasastre en la junta poética llevada a cabo en Toledo durante las fiestas en celebración del nacimiento del futuro Felipe IV: recibió ése un Agnusdei de oro al juzgársele primero en las Octavas; véase Joaquín EnTrambasaGuas, Lope de Vega en las Justas Poéticas toledanas de 1605 y 1608, Madrid, 1969. Aparece este oficial, sin nombre, en el Viaje del Parnaso (cap. 2, vv. 415-417), a quien Cervantes caracteriza como arrojado al mar por Mercurio; sorpende que Vicente Gaos, en su edición del Viaje, Castalia, Madrid, 1974, siguiendo a Rodríguez Marín (edición de 1935), todavía identifique a ese tan mentado poetasastre con “ ¿Un tal Juan Martínez?' aunque la interrogación amengüe el desacierto. El enigma del soneto "Espíritu gentil. .." es resuelto por OTTO JöRDER en "Luis Martín de la Plaza pro und contra Lope de Vega, Eine harmloshibtergrundige Sonettenrache", $Z R P h, 70$ (1954), 98-103. Era conocidísima la afición de Lope por Agustín de Castellanos: chiste obligado en los centros de hablillas. 
(excepto la Tasa) la edición de Flores de poetas ilustres donde se describían los poetas inclusos como "gentiles espíritus del nuestro [tiempo]" y se incluía al desairante Lope de Vega entre "los ilustres ingenios que hoy en España profesan el estudio de la Poesía"24.

No es arriesgado suponer que Cervantes, cuidadoso lector del prólogo de Espinosa a las Flores donde se hallaba implícito un repudio de su condición de "viejo" que ya gozó "su tiempo", y conocedor de la fanfarronada de los elogios en El peregrino de Lope, entre los cuales se incluía un "Espíritu gentil quel alto cielo" ahijado a Agustín de Castellanos, tuvo que desconcertarse o reír ante la concordancia entre el uso del giro "gentiles espíritus de nuestro tiempo" en las Flores y el soneto endosado a un analfabeto en El peregrino. Es también factible que Cervantes, concurridor a los focos de habladurías de la época, tales como el mentidero de Madrid y las academias literarias por él frecuentadas, se hubiera enterado de la suplantación autoral hecha al soneto de Luis Martín de la Plaza, aunque con toda probabilidad, por ser éste de Antequera, no se conociese de nombre. Dentro de ese mundillo literario de dimes y diretes, quien parece surgir incólume es Juan de Arguijo, a quien le adjudican la primacía tanto Lope como Espinosa. Cervantes escogerá al intocable Arguijo como blanco de la saeta 25 .

No nos debe sorprender que para dilucidar el contexto hacia el cual se orienta el soneto "Vuela mi estrecha y débil esperanza" de Cervantes hayamos tenido que desencaminarnos de lo obvio y encaminarnos por tortuosas veredas cuyas encrucijadas obligan a la especulación para llegar a la evidencia. Queda el soneto que aquí escudriñamos como perfeccionamiento de materiales ajenos:

${ }^{24}$ Se desquita Luis Martín de la Plaza al dedicarle al antólogo Juan Antonio Calderón el soneto "Hermosas ninfas que en alegre coro" (Segunda parte de las Flores de poetas ilustres, ms. de 1611) que ya se conocía como regalo del antequerano a Lope de Vega. Lo ingenioso de esta fina venganza se duplica al asentarse el poema como escrito por Pedro Martín de la Plaza, hermano de Luis; véase art. cit. de OTTO JÖRDER.

${ }^{25}$ Cervantes, al mencionarlo en el Viaje del Parnaso ("Entre ellos, [Apolo] abrazó a Don Juan de Arguijo, / que no sé en qué, o cómo, o cuándo hizo / tan áspero viaje y tan prolijo. / Con él a su deso satisfizo / Apolo, y confirmó su pensamiento, / mandó, vedó, quitó, hizo y deshizo"', cap. 3, vv. 352-357), insinúa el carácter privativo, y regalado, del poeta (cf. RodRigo GARO, Varones insignes en letras, naturales de la ilustrísima ciudad de Sevilla, ed. S. Montoto, Sevilla, 1915, p. 73), además de realzar su señorío en fallos críticos mediante el empleo de la fórmula jurídica en los dos últimos versos. 
recursos estilísticos comunes a los parnasistas andaluces, lenguaje herreriano, giros verbales habituales en Arguijo y materia ovidiana. El puente entre el artificio del soneto y los contextos, generadores de tránsitos intertextuales, no cancela el valor estético del poema: el rifacimento cervantino es orgánico a la creación, y el soneto de La entretenida, como sucede en cada caso de reaprovechamiento de materiales ajenos o propios, obedece a un sistema artístico eficaz por sí. Si algo no existe en Cervantes es la falta de invención remediada con el préstamo. El prodigio cervantino radica en su aprovechamiento de lo extraliterario, sublimándolo, reconfigurándolo, entretejiéndolo con otros hilos hasta llegar a una nueva realización.

Convergirán en el soneto estudiado la postura crítica de Cervantes frente a Lope de Vega, trasladada sobre Arguijo, con la queja del desaire implícito en las Flores de poetas ilustres editadas por Pedro de Espinosa ${ }^{26}$, pero no como ligazón sencilla sino co-

${ }^{26}$ Es curioso que en La entretenida aparezcan dos textos cuya procedencia ha sido desconcertante para los anotadores Schevill y Bonilla (Comedias y entremeses, t. 1) y Luis F. Díaz Larios (La entretenida. Pedro de Urdemalas, PPU, Barcelona, 1988). El primer texto incluye la no común alusión a Giovanni Giacomo Médicis, marqués de Marignano: "ser para marqués bastante, / como aquél de Marinán, / de dinare e piu dinare". Schevill y Bonilla lo anotan como de fuente desconocida, aunque señalan el sintagma "piu dinare" como incluso en el entremés Los sacristanes Cosquillas y Talegote de QuiÑones DE BENAVENTE; Díaz Larios sigue a Schevill y Bonilla, añadiéndole unas aclaraciones lingüísticas que no resuelven el problema. Aunque es posible que Cervantes sacase la anécdota aludida de alguna Miscelánea, quizá de los Detti memorabili di personaggi illustri de Grovanni Botero (Turín, 1608), donde se cita al marqués de Marignano, apotegmatizante servidor de Carlos IV, nos parece que el texto cervantino arranca de unos versos al dinero escritos por Diego de la Chica e incluidos en las Flores de poetas ilustres de 1605: "La que más se remontare / tú la trairás a la mano, / cual dice el de Mariñano, / con dinare e piu dinare" (ed. de 1896, p. 57). El segundo texto que nos preocupa es: "No me importa a mí una guinda / pronunciar con dinguindujes", que Schevill y Bonilla anotan sin explicar ("Quizá sea vocablo onomatopéyico. Recuérdese el dingolondangos del Cuento de cuentos, de Quevedo"), mientras Díaz Larios define como "tontería, afectación" e indica su origen como uno de creación expresiva. He encontrado esa voz cervantina únicamente en dos sonetos anónimos burlescos, de indiscutible estirpe andaluza, que juegan con la dislocación acentual resultante en versos agudos con $/ \mathrm{j} /$ ( $x$ ortográfica) final: ambos sonetos se incluyen en el Cancionero antequerano ("¡cuál estuviera ya mi dinganduj!", núm. CCCLXXIII; "Señora, quite alia su dinganduj”, núm. CDXXXIV; pp. 105 y 122 en ed. de D. Alonso y R. Ferreres). Creemos que la relación entre Cervantes y los poetas de Sevilla y Antequera es de importancia: debería estudiarse. 
mo conjunción con querencias propias fundamentadas en el convencimiento de su valía como poeta, dramaturgo y novelista. El arte de Cervantes es un cartel de desafío a la crítica: emerge de una operación alquímica y como tal debe el lector aproximarse al texto.

Adriana Lewis Galanes

Temple University 